\title{
Effectiveness of Geography Teaching Materials Based on Disaster Literacy to Improve Disaster Preparadness
}

\author{
Ulfah Khairani Ramadhan, Sarwono, Chatarina Muryani
}

Universitas Sebelas Maret

Ulfahkhairani8@gmail.com

\section{Article History}

accepted 31/08/2020

approved 22/09/2020

published 28/10/2020

\begin{abstract}
Disaster literacy is integrated in learning in schools such as designing teaching materials that contain disaster literacy in it so that participant preparedness students in dealing with disasters can increase, the purpose of this study is to determine the effectiveness of the use of geography teaching materials based on disaster literacy to improve the readiness of Kerjo Karanganyar high school students in dealing with landslides. The method used in this study is one group pre-test post-test, using the $t$ test analysis or independent sample $t$ test with a confidence level of 5\%, the results of the study are as follows the effectiveness of the use of geography-based disaster literacy teaching materials at a $5 \%$ confidence level $(0,05)$ obtained sig $0.0046<0.05$ which means there is an increase in students' disaster preparedness in all aspects, namely knowledge, attitudes, emergency response plans, disaster warning systems and resource mobilization capabilities.
\end{abstract}

Keywords: Teaching Materials, Disaster Literacy, Disaster Preparedness

\begin{abstract}
Abstrak
Literasi bencana diintegrasikan dalam pembelajaran disekolah seperti merancang bahan ajar yang memuat literasi bencana didalamnya agar kesiapsiagaan peserta didik dalam menghadapi bencana dapat meningkat, tujuan penelitian ini adalah untuk mengetahui evektifitas penggunaan bahan ajar geografi berbasis literasi bencana untuk meningkatkan kesiapsiagaan peserta didik sma kerjo karanganyar dalam menghadapi bencana alam longsor. Metode yang digunakan dalam penelitian ini adalah one group pre test post test, dengan menggunakan analisis uji $t$ atau independent sample $t$ test dengan taraf kepercayaan $5 \%$, hasil penelitian adalah sebagai berikut efektivitas penggunaan bahan ajar geografi berbasis literasi bencana pada taraf kepercayaan $5 \%(0,05)$ diperoleh sig $0,0046<0,05$ yang berarti terdapat peningkatan kesiapsiagaan bencana peserta didik pada semua aspek yaitu pengetahuan, sikap, rencana tanggap darurat, sistem peringatan bencana dan kemampuan mobilisasi sumber daya.
\end{abstract}

Kata kunci: Bahan Ajar, Literasi Bencana, Kesiapsiagaan Bencana.

Social, Humanities, and Education Studies (SHEs): Conference Series https://jurnal.uns.ac.id/shes

p-ISSN 2620-9284

e-ISSN 2620-9292 


\section{PENDAHULUAN}

Tingginya risiko bencana alam yang ada dapat dikurangi dengan meningkatkan kapasitas masyarakat yang terdampak bencana).(Oktari et al., 2015) Peran masyarakat sangat penting dalam upaya pengurangan risiko bencana(Akhirianto, 2019). Bencana terjadi apabila komunitas mempunyai tingkat kemampuan yang lebih rendah dibanding dengan tingkat ancaman yang mungkin terjadi padanya. Ancaman menjadi bencana apabila komunitas rentan, atau memiliki kapasitas lebih rendah dari tingkat bahaya tersebut, atau bahkan menjadi salah satu sumber ancaman tersebut. (Coburn et al., 1994)Hal ini dikarenakan dengan ancaman dan bahaya yang sama, jika kapasitas dari masyarakat yang terdampak bencana bisa ditingkatkan maka risiko dipastikan mampu berkurang hal ini sesuai dengan pedoman umum Pengkajian Risiko Bencana yang digunakan oleh BNPB dalam mentukan indeks risiko bencana dengan menggabungkan nilai indeks bahaya, kerentanan, dan kapasitas (RBI BNPB 2016).

Untuk mengurangi risiko bencana diperlukan adanya pengetahuan mengenai bencana atau lebih sering disebut dengan literasi bencana (Disaster Literacy)(AlMaraghi et al., 2017). Listerasi bencana merupakan study bencana berbasis komunitas yang sangat cocok diterapkan di indonesia yang sangat rentan terhadap bencana, membelajarkan atau memberikan pengetahuan kepada suatu komunitas mengenai bencana.(Morrison et al., 2016) Literasi Bencana atau bisa disebut upaya penyadaran masyarakat dalam menghadapi suatu bencana, tentulah sangat penting dimiliki oleh masyarakat. Hal tersebut dilakukan dalam rangka memitigasi suatu bencana. (Marlyono, 2017). Literasi bencana atau melek bencana memang tidak dapat menghentikan terjadinya bencana itu sendiri, akan tetapi hal itu dapat membantu kita mempersiapkan diri menghadapi bencana tersebut sehingga akan mengurangi dampak kerugian yang ditimbulkannya (Marlyono et al., 2016).

Sekolah merupakan salah satu bagian dari kelompok masyarakat yang juga sangat berperan dalam pengurangan risiko bencana terutama pada peningkatan kapasitas. Sekolah menjadi tempat yang sangat tepat untuk pendidikan bencana. Literasi bencana memberikan dasar mengenai penting dan sangat dibutuhkannya pendidikan pencegahan bencana, pengurangan risiko dan penyelamatan bencana. Hal ini didukung oleh Organisasi kependidikan PBB bersama dengan Strategi Internasional PBB untuk Pengurangan Risiko Bencana (UNSDR), semenjak tahun 2006 mulai mempromosikan pendidikan pencegahan bencana dengan memasukkan pengetahuan pengurangan risiko bencana kedalam kurikulum sekolah serta mendorong penerapan pembangunan yang memperhitungkan ancaman bencana.(Chan et al., 2012) Salah satu penerapan pendidikan pencegahan bencana adalah dengan memasukkan literasi bencana kedalam materi pembelajaran atau bahan ajar peserta didik. "Bahan ajar harus disusun secara sistematis, menarik, aspek keterbacaan tinggi, mudah dicerna, dan mematuhi aturan penulisan yang berlaku.(Farhatin et al., 2020) Bahan ajar yang tersusun secara sistematis akan mempermudah peserta didik dalam menerima materi, sehingga mendukung ketercapaian tujuan pembelajaran (Hall, 2012).

\section{METODE}

Metode yang digunakan dalam penelitian ini adalah one group pretest posttest, merupakan tahapan lanjutan dari penelitian pengembangan menurut Ploomp(Saseno1, Pramono Giri Kriswoyo2, 2020). Populasi dalam penelitian ini adalah peserta didik SMA N Kerjo. Penilaian dilakukan dengan metode skoring melalui instrument angket. Penilaian menggunakan skala Guttman yaitu pilihan jawaban "Ya" dan "Tidak". (Suranto et al., 2004). Jumlah pertanyaan pada masing-masing parameter tidak sama disesuaikan dengan indikator setiap parameter kesiapsiagaan. Total skor rill yang diperoleh dengan menjumlahkan skor setiap indikator dimasing-masing parameter yang bersangkutan. Tingkat kesiapsiagaan dalam kajian ini dikategorikan menjadi lima kategori sebagai berikut : 
Tabel 1. Kelas Kesiapsiagaan

\begin{tabular}{ccl}
\hline No & Nilai Indeks & \multicolumn{1}{c}{ Ketegori } \\
\hline 1 & $80-100$ & Sangat Siap \\
2 & $65-79$ & Siap \\
3 & $55-64$ & Hampir Siap \\
4 & $40-54$ & Kurang Siap \\
5 & $<40$ & Belum Siap \\
\hline Sumber : LIPI-UNESCOISDR 2006
\end{tabular}

Selain menggunakan perbandingan pretest dengan posttest dalam penelitian ini juga meggunakan teknik analisis deskriptif komparatif dengan menggunakan statistik parametrik uji sample T test(Nainggolan, 2009). Uji T test sebagai statistik parametrik memerlukan uji prasyarat yang terdiri dari uji normalitas data untuk mengetahui analisis data untuk pengujian hipotesis dapat dilanjutkan atau tidak. Hasil uji normalitas dengan Kolmogorov Smirnov diperoleh harga statistik Uji L (liliefors) untuk taraf signifikasi 0,05 (Sundari, 2017).

\section{HASIL DAN PEMBAHASAN}

Penanganan bencana yang bersifat responsif kurang efektif dalam mengurangi risiko bencana, terbukti masyarakat tetap panik ketika bencana alam kembali terjadi di daerah rawan bencana alam(Hidayati, 2008) Kurangnya pengetahuan dan minimnya informasi mengenai fenomena alam yang terjadi di sekitar(Hidayatr, 2009). Pendidikan untuk mengurangi risiko akibat bencana sangat penting dan perlu disosialisasikan pada masyarakat agar korban saat terjadi bencana dapat diminimalkan. Sosialisasi pendidikan mitigasi bencana sejak dini dapat dilakukan di sekolah melalui metode yang tepat(Nirwansyah \& Nugroho, 2015). Salah satu penangaan bencana alam pada jenjang sekolah dasar dan menengah adalah penggunaan bahan ajar berbasiskan pada literasi bencana (Marlyono et al., 2016). Literasi bencana mengacu pada seseorang yang terlibat dalam memahami aspek sosial dan lingkungan dalam risiko, dan kebutuhan akan sumber daya yang menyimpan dan memulihkan secara permanen (Brown \& Haun, 2014) (Brown et al., 2014). Jika kita melihat model literasi bencana oleh Brown et al (2014), kita dapat menggunakan dua pendekatan penelitian, yaitu penelitian efektivitas komparatif dan evaluasi bahan komunikasi.(Chu et al., 2019) Dalam model, penelitian efektivitas komparatif adalah bagian dari evaluasi penelitian bahan komunikasi.(Shih et al., 2012)

Sebelum diterapkan dalam pembelajaran perlu diketahui keefektifan dari bahan ajar yang akan digunakan(Hernawan et al., 2008). Evektifitas penggunaan bahan ajar geografi berbasis literasi dilihat perbandingan hasil kesiapsiagaan peserta didik dalam menghadapi bencana paling sering terjadi di karanganyar yaitu bencana longsor lahan(Cholil et al., 2018) Hasil yang dibandingkan adalah kesiapsiagaan bencana longsor peserta didik sebelum dan sesudah menggunakan bahan ajar geografi berbasis literasi bencana. Sebelum dilakukannya proses pembelajaran menggunakan bahan ajar geografi dilakukan pretest kesiapsiagaan peserta didik, hal ini untuk mengetahui kesiapsiagaan awal peserta didik dalam menghadapi bencana yang ada di sekeliling mereka, hasil kesiapsiagaan awal peserta didik kelas XI IPS 1 sebagai berikut 
Tabel 2. Hasil Kesiapsiagaan Awal kelas XI IPS 1

\begin{tabular}{cccc}
\hline No & Nilai Indeks & Kategori & Frekuensi \\
\hline 1 & $80-100$ & Sangat Siap & 0 \\
2 & $65-79$ & Siap & 1 \\
3 & $55-64$ & Hampir siap & 6 \\
4 & $40-54$ & Kurang Siap & 11 \\
5 & $<40$ & Tidak Siap & 18 \\
\hline
\end{tabular}

Sumber : Hasil analisis data primer 2020

Dari tabel dapat diketahui bahwa sebelum menggunakan bahan ajar geografi berbasis literasi bencana 18 peserta didik (50\%) tidak siap, 11 peserta didik $(30 \%)$ kurang siap, 6 peserta didik (17\%) peserta didik hampir siap, 1 peserta didik (3\%) belum siap, dan tidak satupun peseta didik yang memiliki kesiapsiagaan pada kategori sangat siap. Rendahnya kesiapsiagaan bencana yang dimiliki oleh peserta didik dikarenakan kurangnya keselarasan antara tuntutan literasi dari materi kesiapsiagaan bencana dan pemulihan yang ada (Daramola et al., 2017) dan keterampilan literasi dari kelompok rentan (peserta didik) membatasi kemampuan mereka untuk memahami dan secara efektif menggunakan informasi yang berpotensi meningkatkan kesiapsiagaan dalam mengadapi bencana (Brown \& Haun, 2014), baik memperispapkan diri sebelum bencana terjadi, saat teerjadi bencana dan pemulihan pasca bencana.(Brown et al., 2014) Untuk mengetahui keefektifan bahan ajar geografi berbasis literasi dibandingkan dengan kenaikan persentase kesiapsiagaan peserta didik di kelas yang sama, setelah menggunakan bahan ajar geografi berbasis literasi bencana tersebut. Hasil kesiapsiagaan peserta didik setelah menggunakan bahan ajar geografi berbasis literasi bencana sebagai berikut :

Tabel 3. Posttest Kesiapsiagaan Bencana Peserta Didik

\begin{tabular}{cccc}
\hline No & Nilai Indeks & Kategori & Frekuensi \\
\hline 1 & $80-100$ & Sangat Siap & 0 \\
2 & $65-79$ & Siap & 18 \\
3 & $55-64$ & Hampir siap & 13 \\
4 & $40-54$ & Kurang Siap & 5 \\
5 & $<40$ & Tidak Siap & 0 \\
\hline \multicolumn{2}{l}{ Sumber : Hasil analisis data primer 2020} &
\end{tabular}

Dari tabel di atas dapat dilihat bahwa kesiapsiagaan peserta didik setelah menggunakan bahan ajar geografi berbasis literasi bencana adalah 5 peserta didik (14\%) kurang siap, 13 peserta didik (36\%) hampir siap, 18 peserta didik (50\%) peserta didik siap, tidak ada peserta didik yang memiliki kesiapsiagaan tidak siap dan sangat siap menghadapi bencana longsor. Peningkatan kesiapsiagaan bencana ini dapat diasumsikan bahwa kemampuan individu untuk membaca, memahami, dan menggunakan informasi untuk membuat keputusan yang tepat dan mengikuti instruksi dalam konteks mitigasi, persiapan, respons, dan pemulihan dari bencana juga sudah 
meningkat.(Torri \& Poesen, 2014). Perbedaan kesiapsiagaan peserta didik sebelum dan setelah menggunakan bahan ajar geografi berbasis literasi bencana dapat dilihat dalam tabel dan diagram sebagai berikut:

Tabel 4 Perbandingan Pretest Dan Posttest Kesiapsiagaan Kelas XI IPS I

\begin{tabular}{llllll}
\hline Aspek & $\begin{array}{c}\text { Sangat } \\
\text { Siap }\end{array}$ & \multicolumn{1}{c}{ Siap } & $\begin{array}{c}\text { Hampir } \\
\text { Siap }\end{array}$ & $\begin{array}{c}\text { Kurang } \\
\text { Siap }\end{array}$ & Tidak Siap \\
\hline Pretest & $0 \%$ & $3 \%$ & $17 \%$ & $30 \%$ & $18 \%$ \\
Posttest & $0 \%$ & $50 \%$ & $36 \%$ & $14 \%$ & $0 \%$ \\
\hline
\end{tabular}

Sumber : hasil analisis data primer 2020

Berdasarkan tabel 4 kenaikan persentase kesiapsiagaan peserta didik kelas XI IPS 1 setelah menggunakan bahan ajar geografi berbasis literasi bencana dapat dilihat dalam diagram berikut ini :

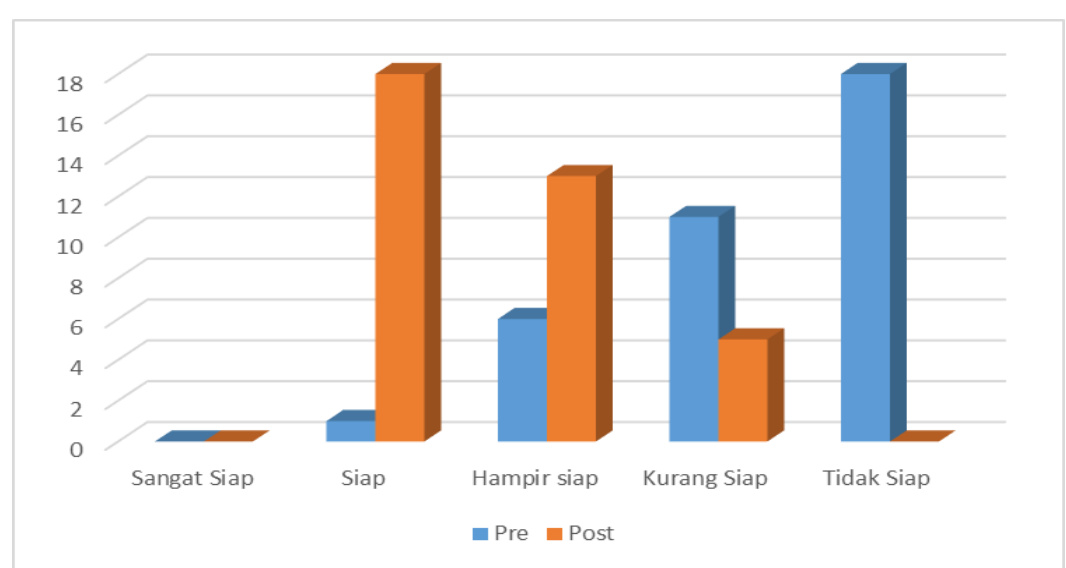

Gambar 1 Perbandingan Pretest dan Posttest Kesiapsiagaan Bencana

Tabel 5 Uji independent Test Kesiapsiagaan bencana

\begin{tabular}{|c|c|c|c|c|c|c|c|c|c|}
\hline \multicolumn{10}{|c|}{ Independent Sampels Test } \\
\hline & \multicolumn{2}{|c|}{$\begin{array}{c}\text { Levene's Test for } \\
\text { Equality of } \\
\text { Variances }\end{array}$} & \multicolumn{7}{|c|}{ t-test for Equality of Means } \\
\hline & \multirow[t]{2}{*}{$\mathrm{F}$} & \multirow[t]{2}{*}{ Sig. } & \multirow[t]{2}{*}{$\mathrm{t}$} & \multirow[t]{2}{*}{ Df } & \multirow{2}{*}{$\begin{array}{l}\text { Sig. (2- } \\
\text { tailed) }\end{array}$} & \multirow{2}{*}{$\begin{array}{c}\text { Mean } \\
\text { Differenc } \\
\text { e }\end{array}$} & \multirow[t]{2}{*}{$\begin{array}{l}\text { Std. Error } \\
\text { Difference }\end{array}$} & \multicolumn{2}{|c|}{$\begin{array}{l}95 \% \text { Confidence } \\
\text { Interval of the } \\
\text { Difference }\end{array}$} \\
\hline & & & & & & & & Lower & Upper \\
\hline $\begin{array}{c}\text { Equal } \\
\text { variances } \\
\text { assumed }\end{array}$ & 14.444 & .000 & 2.041 & 70 & .045 & 5.64167 & 2.76406 & .12893 & 11.15441 \\
\hline $\begin{array}{c}\text { Equal } \\
\text { variances } \\
\text { not } \\
\text { assumed }\end{array}$ & & & 2.041 & 50.70 & .046 & 5.64167 & 2.76406 & .09181 & 11.19152 \\
\hline
\end{tabular}

Sumber : Hasil Analisis Data Primer 2020 
Berdasarkan tabel 5 efektifitas penggunaan bahan ajar geografi berbasis literasi bencana untuk meningkatkan kesiapsiagaan peserta didik pada taraf kepercayaan $5 \%$ $(0,05)$ diperoleh Sig $0.046<0,05$ yang berarti Ha diterima, dan terdapat peningkatan kesiapsiagaan peserta didik setelah menggunakan bahan ajar geografi berbasis literasi bencana.

\section{SIMPULAN}

Literasi bencana didefinisikan sebagai kemampuan individu untuk membaca, memahami, dan menggunakan informasi untuk membuat keputusan yang tepat dan mengikuti instruksi dalam konteks mitigasi, persiapan, respons, dan pemulihan dari bencana. Rekomendasi dibuat untuk mengembangkan dan mengevaluasi materi komunikasi bencana untuk populasi yang rentan. Untuk memenuhi dan meningkatkan literasi bencana pada populasi rentan, kami menyarankan penggunaan bahan ajar geografi berbasis literasi yang sudah diuji keefektivannya. Efektivitas penggunaan bahan ajar geografi berbasis literasi bencana diketahui melalui one group pretest posttest desain. Efektivitas penggunaan bahan ajar geografi berbasis literasi bencana pada taraf kepercayaan 5\% $(0,05)$ diperoleh Sig 0,0046<0,05 yang berarti terdapat peningkatan kesiapsiagaa bencana longsor peserta didik setelah menggunakan bahan ajar geografi dalam proses pembelajaran.

\section{DAFTAR PUSTAKA}

Akhirianto, N. A. (2019). Konsep Desain Pengurangan Risiko Bencana Longsor Berbasis Komunitas. Jurnal Sains Dan Teknologi Mitigasi Bencana, 12(1), 32. Https://Doi.Org/10.29122/Jstmb.V12i1.3698

Al-Maraghi, F. A., Rochman, C., \& Suhendi, H. Y. (2017). Profil Literasi Peserta Didik Terhadap Mitigasi Bencana Gunung Berapi Di Daerah Sukaratu Tasikmalaya. $\begin{array}{llll}\text { Wapfi (Wahana Pendidikan } & \end{array}$ Https://Doi.Org/10.17509/Wapfi.V2i2.8275

Brown, L. M., \& Haun, J. (2014). Literacy And Disaster Preparedness For Seniors. In Disaster Preparedness For Seniors (Pp. 249-260). Https://Doi.Org/10.1007/978-14939-0665-9_17

Brown, L. M., Haun, J. N., \& Peterson, L. (2014). A Proposed Disaster Literacy Model. Disaster Medicine And Public Health Preparedness. Https://Doi.Org/10.1017/Dmp.2014.43

Chan, E. Y. Y., Hung, K. C. K., Yue, J., Kim, J. H., Lee, P., \& Cheung, E. Y. (2012). Preliminary Findings On Urban Disaster Risk Literacy And Preparedness In A Chinese Community. The 13th World Congress On Public Health, 117. Https://Wfpha.Confex.Com/Wfpha/2012/Webprogram/Paper9563.Html

Cholil, M., Hardjono, I., \& Rudiyanto. (2018). Analisis Resiko Bencana Dan Kerawanan Tanah Longsor Berbasis Tata Ruang Di Kabupaten Karanganyar. Prosiding Seminar Nasional Pendidikan Geografi Fkip Ump 2018, 2002, 139-152.

Chu, Y. M., Chang, T. C., Tsai, C. C., \& Lin, H. L. (2019). Study Of Disaster Prevention Education For Senior Vocational High School Sustainable Campus In Taiwan. Proceedings Of The 2018 leee International Conference On Advanced Manufacturing, Icam 2018, 418-421. Https://Doi.Org/10.1109/Amcon.2018.8615016

Coburn, A. W., Spence, R. J. S., \& Pomonis, A. (1994). Mitigasi Bencana. Disaster $\begin{array}{lll}\text { Management Training Program, } & \end{array}$ Http://Rovicky.Files.Wordpress.Com/2009/10/Mitigasi-Bencana.Pdf

Daramola, O., Odunsi, O., \& Olowoporoku, O. (2017). The Corridor To Survival: Assessment Of Disaster Management Literacy In A Developing Country. Environmental Quality Management, 27(2), 15-24. Https://Doi.Org/10.1002/Tqem.21525 
Farhatin, N., Pujiastuti, H., \& Mutaqin, A. (2020). Pengembangan Bahan Ajar Matematika Berbasis Kearifan Lokal Untuk Siswa Smp Kelas Viii. Prima: Jurnal Pendidikan Matematika, 4(1), 33. Https://Doi.Org/10.31000/Prima.V4i1.2082

Hall, S. (2012). Pengembangan Bahan Ajar Non Cetak Berbasis Ebook Dengan Aplikasi Adobe Captivate 3.0 Untuk Kelas Viii Smp Negeri 1 Cilimus. Iain Syekh Nurjati Cirebon, 66, 37-39.

Hernawan, A. H., Permasih, \& Dewi, L. (2008). Panduan Pengembangan Bahan Ajar. In

Http://File.Upi.Edu/Direktori/Fip/Jur._Kurikulum_Dan_Tek._Pendidikan/194601291 981012-Permasih/Pengembangan_Bahan_Ajar.Pdf

Hidayati, D. (2008). Paradigma Baru Pengèlolaan Bencana Alam Di Indonesia. Kependudukan Indonesia, lii(I), 69-84. Https://Doi.Org/Https://Doi.Org/10.14203/Jki.V3i1.164

Hidayatr, D. (2009). Kesiapsiagaan Masyarakat: Paradigma Baru Pengelolaan Bencana Alam. Jurnal Kependudukan Indonesia, 3(1), 69-84. Https://Doi.Org/10.14203/Jki.V3i1.164

Marlyono, S. G. (2017). Pengaruh Literasi Informasi Bencana Terhadap Kesiapsiagaan Masyarakat Dalam Menghadapi Bencana Di Provinsi Jawa Barat. Jurnal Geografi Gea, 16(2), 116. Https://Doi.Org/10.17509/Gea.V16i2.4491

Marlyono, S. G., Pasya, G. K., \& Nandi. (2016). Peranan Literasi Informasi Bencana Terhadap Kesiapsiagaan Bencana Masyarakat Jawa Barat. Gea. Jurnal Pendidikan Geografi, 16(2), 116-123.

Morrison, F. J., Marks, R. A., Woods, A. D., \& Connor, C. M. (2016). Literacy. In The Curated Reference Collection In Neuroscience And Biobehavioral Psychology. Https://Doi.Org/10.1016/B978-0-12-809324-5.05837-5

Nainggolan, B. M. (2009). Perbandingan Uji Tukey (Uji Beda Nyata Jujur (Bnj)) Dengan Uji Fisher (Uji Beda Nyata Terkecil (Bnt)) Dalam Uji Lanjut Data Rancangan Percobaan. Majalah IImiah Panorama Nusantara, 7, 11-17.

Nirwansyah, A. W., \& Nugroho, A. (2015). Pengembangan Model Pembelajaran Mitigasi Bencana Gunungapi Slamet Bagi Siswa Mi Muhammadiyah Singasari. Prosiding Seminar Nasional Pendidikan Geografi Fkip Ump 2015, 36-40.

Oktari, R. S., Kumala, I. D., Rachmalia, \& Husna, N. (2015). Penguatan Kapasitas Kelembagaan Sekolah Dalam Upaya Meningkatkan Ketahanan Masyarakat Terhadap Bencana. Simposium Nasional, Mitigasi Bencana Tsunami 2015., December 2015, 21-22. Https://Www.Researchgate.Net/Publication/293029947

Saseno1, Pramono Giri Kriswoyo2, H. (2020). One Group Pre-Test Post-Test Design. Efektifitas Relaksasi Terhadap Tingkat Kecemasan Pada Lansia Di Posyandu Lansia Adhi Yuswa Rw. X Kelurahan Kramat Selatan, 60-67.

Shih, B. Y., Chen, C. Y., Chen, C. W., \& Hsin, I. (2012). Using Lego Nxt To Explore Scientific Literacy In Disaster Prevention And Rescue Systems. Natural Hazards, 64(1), 153-171. Https://Doi.Org/10.1007/S11069-012-0233-2

Sundari, J. (2017). Pengaruh Model Pembelajaran Kooperatif Tipe Make A Match Terhadap Kemampuan Komunikasi Matematis Siswa. Jkpm (Jurnal Kajian Pendidikan Matematika), 2(2), 227. Https://Doi.Org/10.30998/Jkpm.V2i2.2496

Suranto, Musrovi, M., \& Widodo, A. (2004). Analisis Kepuasam Konsumen Dengan Skala Guttman. IImiah Teknik Industri, 03(2), 36-47. Https://Doaj.Org/Article/6bb6a59bdc2641278014542dca86fb09

Torri, D., \& Poesen, J. (2014). A Review Of Topographic Threshold Conditions For Gully Head Development In Different Environments. In Earth-Science Reviews (Vol. 130, Pp. 73-85). Https://Doi.Org/10.1016/J.Earscirev.2013.12.006 